\title{
A novel LC-ESI-MS method for the simultaneous determination of etravirine, darunavir and ritonavir in human blood plasma
}

\author{
Naser L. Rezk ${ }^{*}$, Nicole R. White, Steven H. Jennings, and Angela D.M. Kashuba \\ Clinical Pharmacology/Analytical Chemistry Core, Center for AIDS Research, University of North \\ Carolina at Chapel Hill, Chapel Hill, NC 27599, United States
}

\begin{abstract}
The new potent combination of antiretrovirals etravirine, darunavir, and ritonavir requires a new bioanalytical method for clinical pharmacology investigations and potential therapeutic drug monitoring. The development and validation of a novel LC-MS method for the simultaneous quantification of the most recently FDA-approved protease inhibitor and non-nucleoside reverse transcriptase inhibitor is described. This novel method was developed and validated using a sub-2 $\mu \mathrm{m}$ particle column, and provides excellent chromatographic separation and peak shape for all three analytes and internal standard. The method was validated over the range of $0.002-2.0 \mu \mathrm{g} / \mathrm{mL}$. Intraand inter-day accuracy of all analytes ranged from 88 to $106 \%$, and intra- and inter-day precision was $<7 \%$. Dilution of samples 2-, 5-, and 10-fold maintained accuracy and precision, using a sample volume as low as $10 \mu \mathrm{L}$. Finally, the applicability of the method was investigated with clinical samples and external quality assurance proficiency testing samples.
\end{abstract}

\section{Keywords}

Etravirin; Darunavir; Ritonavir; HIV; Antiretroviral agent; Mass spectrometry

\section{Introduction}

\begin{abstract}
Etravirine (ETR; Intelence ${ }^{\mathrm{TM}}$ ) is a new non-nucleoside reverse transcriptase inhibitor of human immunodeficiency virus type 1 (HIV-1) [1,2]. The chemical name of etravirine is 4-[[6amino-5-bromo-2-[(-4-cyanophynyl) amino]-4-pyrimidinyl]oxy]-3,5-dimethylbenzonitrile (Fig. 1). ETR is a highly potent inhibitor of HIV-1 replication, with activity in the nanomolar range comparable to that of the commonly prescribed NNRTI efavirenz [2].

Darunavir (DRV; Prezista ${ }^{\mathrm{TM}}$ ) is a new protease inhibitor of HIV-1 [3,4]. The chemical name of darunavir is [(1S,2R)-3-[[(4-aminophenyl)sulfonyl] (2-methylpropyl)amino]-2-hydroxy-1 (phenylmethyl)propyl]-carbamic acid (3R,3aS,6aR)-hexahydofuro[2,3-b]furan-3-yl ester monoethanolate (Fig. 1). DRV is also a potent inhibitor of HIV-1 replication, particularly active against strains with multiple protease inhibitor resistance mutations [5-10].
\end{abstract}

\footnotetext{
(C) 2009 Elsevier B.V. All rights reserved.

* Corresponding author at: 2405 Kerr Hall, CB\# 7360, University of North Carolina at Chapel Hill, Chapel Hill, NC 27599, United States. Tel.: +1 919843 0596; fax: +1 919962 0644. naser2@unc.edu (N.L. Rezk)..

Publisher's Disclaimer: This article appeared in a journal published by Elsevier. The attached copy is furnished to the author for internal non-commercial research and education use, including for instruction at the authors institution and sharing with colleagues. Other uses, including reproduction and distribution, or selling or licensing copies, or posting to personal, institutional or third party websites are prohibited. In most cases authors are permitted to post their version of the article (e.g. in Word or Tex form) to their personal website or institutional repository. Authors requiring further information regarding Elsevier's archiving and manuscript policies are encouraged to visit: http://www.elsevier.com/copyright
} 
For maximum efficacy and durability, antiretrovirals must be used in combination [11-13]. However, treatment failure due to HIV drug resistance mutations is common [14-16]. New therapies, such as ETR and DRV, are aimed at treating patients harboring drug resistant HIV-1 variants. DRV must be given with ritonavir (RTV, Fig. 1) to enhance systemic drug exposure. Recently, the combination of ETR, DRV, and RTV has been demonstrated safe and effective in small numbers of highly drug resistant HIV-infected individuals $[17,18]$.

Further pharmacologic study, including therapeutic drug monitoring (TDM), of these drugs require an accurate and sensitive bioanalytical method. To date, there has been no published LC-MS method for the simultaneous quantification of ETR, DRV, and RTV in human biological fluids. Consequently, this paper describes the development and validation of such a method in human blood plasma using HPLC with electrospray ionization and mass spectrometry detection and (ESI-MS) after a simple liquid-liquid extraction procedure.

\section{Materials and methods}

\subsection{Chemicals}

Etravirine, darunavir ethanolate and ritonavir (Fig. 1) were obtained from the NIH AIDS Research \& Reference Reagent Program (McKesson HBOC BioServices, Rockville, MD, USA). Alprazolam (Fig. 1) was used as an internal standard and was purchased from Sigma Chemical Company (St. Louis, MO, USA). Tertiary butyl methyl ether and HPLC-grade chemicals and HPLC-grade water were purchased from Fisher Scientific (Norcross, GA, USA). Purified compressed nitrogen gas used was obtained from National Welders Supply (Charlotte, NC, USA). Sodium EDTA (Biological Specialty Corporation, Colmar, PA, USA).

\subsection{Equipments}

An Eppendorf 5415D centrifuge (Eppendorf AG, Hamburg, Germany) was used for centrifugation during sample preparation. A high-performance liquid chromatography (HPLC) system consisting of an Agilent Technologies (Wilmington, DE, USA) HP1100 binary pump, degasser, thermostatic auto sampler was connected to an 1100 Series mass spectrometer using positive electrospray ionization. Chromatographic data analysis was performed by HP ChemStation software (Version A.09.03) run on a Dell computer (operated by Windows 2000 professional).

\subsection{Preparation of standards}

Two individual $1 \mathrm{mg} / \mathrm{mL}$ stock solutions of each compound were prepared. To prepare the DRV solution, $5.4 \mathrm{mg}$ of darunavir ethanolate $(593.73 \mathrm{~g} / \mathrm{mol})$ powder, with $99.5 \%$ purity, was accurately weighed and dissolved in a $5 \mathrm{~mL}$ volumetric flask using a solution of 1:1 solution of methanol:HPLC-grade water. To prepare the ETR solution which is less water soluble, 5.0 $\mathrm{mg}$ of ETR $(435.29 \mathrm{~g} / \mathrm{mol})$ powder, with $100 \%$ purity, was dissolved in $5 \mathrm{~mL}$ of a $4: 1$ solution of methanol:HPLC-grade water. To prepare the RTV solution, $5.0 \mathrm{mg}$ of RTV $(720.96 \mathrm{~g} / \mathrm{mol})$ powder, with $100 \%$ purity, was dissolved in $5 \mathrm{~mL}$ of a 1:1 solution of methanol:HPLC-grade water.

A100 $\mu \mathrm{g} / \mathrm{mL}$ composite master stock solution was prepared by combining $1 \mathrm{~mL}$ of each separate analyte stock solution in a $10 \mathrm{~mL}$ volumetric flask, and adjusting the volume with a 4:1 solution of methanol:HPLC-grade water. This composite master stock solution was used to prepare seven intermediate calibrators (in a 4:1 solution of methanol:HPLC-grade water) in concentrations of $0.02,0.1,0.2,1,2,10,20$ and $2 \mu \mathrm{g} / \mathrm{mL}$. Seven calibrators working solutions in concentrations of $0.002,0.01,0.02,0.1,0.2,1.0$ and $2.0 \mu \mathrm{g} / \mathrm{mL}$ were prepared in plasma by diluting the seven intermediate calibrators 1:9 in drug free plasma. This plasma matrix was obtained from whole blood anticoagulated with sodium EDTA. 
From another $100 \mathrm{mg} / \mathrm{mL}$ composite master stock solution, four intermediate solutions in concentrations of $0.06,0.6,6$ and $18 \mu \mathrm{g} / \mathrm{mL}$ were prepared in a $4: 1$ solution of methanol:HPLCgrade water. Four quality control (QC) working solutions in concentrations of 0.006, 0.06, 0.6 and $1.8 \mu \mathrm{g} / \mathrm{mL}$ were prepared in plasma by diluting the four intermediate solutions $1: 9$ in drug free plasma.

A composite $50 \mu \mathrm{g} / \mathrm{mL}$ master stock solution containing sixteen potential drugs of interference (primarily other protease inhibitors, non-nucleoside reverse transcriptase inhibitors, nucleoside reverse transcriptase inhibitors, raltegravir and maraviroc) was prepared from individual $1 \mathrm{mg} /$ $\mathrm{mL}$ primary stock solutions of each drug. This solution was prepared using a 3:1 solution of methanol:HPLC-grade water, and diluted in the final reconstitution solution (as described below) to $0.1 \mu \mathrm{g} / \mathrm{mL}$ before injection onto the HPLC system.

\subsection{Internal standard (IS) preparation}

A stock solution of alprazolam was prepared by dissolving $10 \mathrm{mg}$ in a $10 \mathrm{~mL} 1: 1 \mathrm{of} 10 \mathrm{~mL}$ of methanol:HPLC-water solution to achieve a final concentration of $1.0 \mathrm{mg} / \mathrm{mL}$. A $0.1 \mathrm{~mL}$ aliquot of this solution was further diluted in $100 \mathrm{~mL} \mathrm{HPLC}$-water to a final working solution concentration of $0.1 \mu \mathrm{g} / \mathrm{mL}$.

\subsection{Sample pre-treatment}

Blood samples were collected in sodium EDTA tubes and, within 30 min of collection, were centrifuged at $2800 \mathrm{rpm}$ for $15 \mathrm{~min}$ at $4{ }^{\circ} \mathrm{C}$. Plasma was transferred to clean cryovials and stored at $-70^{\circ} \mathrm{C}$ until analysis. Prior to extraction, all plasma samples were heated for $60 \mathrm{~min}$ at $58^{\circ} \mathrm{C}$ to inactivate HIV.

\subsection{Liquid-liquid extraction}

On the day of analysis, all samples and reagents were brought to room temperature. Aliquots $(100 \mu \mathrm{L})$ of patient samples, quality control (QC) solutions, calibrators, and blank plasma were transferred to $2.0 \mathrm{~mL}$ conical Eppendorf centrifuge tubes containing $100 \mu \mathrm{L}$ of the internal standard working solution. Subsequently, $1.5 \mathrm{~mL}$ of tertiary butyl methyl ether was added to each tube. All tubes were capped, vortex-mixed for $10 \mathrm{~min}$, and centrifuged at 12,000 rpm for $3 \mathrm{~min}$ at room temperature. The tubes were placed in a dry-ice and acetone bath for at least 1 min to freeze the aqueous layer. The liquid organic layer was then transferred to a labeled 1.7 $\mathrm{mL}$ Eppendorf tube and placed in a $45^{\circ} \mathrm{C}$ water bath under a nitrogen stream for approximately $10 \mathrm{~min}$. The residue was reconstituted with $100 \mu \mathrm{L}$ of a 1:3 solution of mobile phase A: mobile phase B (see below), sonicated for $10 \mathrm{~s}$, vortex-mixed for $30 \mathrm{~s}$, and centrifuged at 12,000 rpm at room temperature for $5 \mathrm{~min}$. The supernatants were transferred to $200 \mu \mathrm{L}$ HPLC microvials (Agilent Technologies) and $3 \mu \mathrm{L}$ were injected onto the column.

\subsection{Separation conditions}

2.7.1. High-performance liquid chromatographic conditions-The chromatographic separation of DRV, ETR, RTV, and the IS was performed on an Agilent Zorbax® XDB C-8 $(50 \mathrm{~mm} \times 3.0 \mathrm{~mm}, 1.8 \mu \mathrm{m})$ column with an Agilent RRLC in-line filter. Mobile phase A consisted of $0.01 \%$ formic acid in water, and mobile phase B consisted of $0.01 \%$ formic acid in acetonitrile. A linear gradient elution was performed from 35 to $65 \%$ mobile phase B over $6 \mathrm{~min}$, with $1 \mathrm{~min}$ at $100 \%$ mobile phase B for column washing, followed by $3 \mathrm{~min}$ of reequilibration time using 36\% mobile phase B. Over the first $6 \mathrm{~min}$, the gradient mobile phase flow rate increased from 0.65 to $0.75 \mathrm{~mL} \mathrm{~min}^{-1}$. During the wash, the flow rate remained at $0.75 \mathrm{~mL} \mathrm{~min}-1$ and returned to $0.65 \mathrm{~mL} \mathrm{~min}^{-1}$ during the reequilibration phase. 
2.7.2. Mass spectrometric conditions-Mass spectral analysis was performed on an Agilent quadruple 1100 mass spectrometer, fitted with an electrospray ionization (ESI) source and operated in the positive ionization mode. The vaporizer operated at $350{ }^{\circ} \mathrm{C}$; the nebulizer gas pressure was set to $40 \mathrm{psig}$ and the capillary voltage set to $4000 \mathrm{~V}$. The IS, DRV, RTV, and ETR were detected by their positive ion $(\mathrm{m} / \mathrm{z} 309.0,548.2,721.3$ and 435.0, respectively) with single ion monitoring.

2.7.3. Mobile phase optimization-Direct injections of a composite solution of the IS, DRV, RTV, and ETR at a concentration of $1 \mu \mathrm{g} / \mathrm{mL}$ was used to determine the optimum mobile phase modifier. Four concentrations of formic acid $(0.01,0.05,0.1$ and $0.2 \%)$ and four concentrations of ammonium acetate $(0,10,15,25 \mathrm{mM})$ were tested.

\subsection{Assessment of performance characteristics}

2.8.1. Linearity-Calibration standards were prepared and analyzed in duplicate in six independent runs. Daily standard curves were constructed for each drug using the ratio of the observed peak area for each analyte to the internal standard peak area. Unknown concentrations were computed from the linear regression equations of the peak area ratio against the concentration of each analyte. An equal weighted regression was used to assess linearity; deviation of the mean calculated concentrations over three runs were required to be within $15 \%$ of the nominal concentrations for the non-zero calibration standards.

2.8.2. Specificity and selectivity-Interference from endogenous compounds was investigated by analysis of six male and female blank plasma samples. Interference from sixteen commonly used antiretroviral medications was also investigated (as described above).

2.8.3. Accuracy and precision-Accuracy and intra- and inter-day precision of the method were determined by assaying six replicates of each of the spiked QC samples in three separate analytical runs. Samples included the low limit of quantitation (LOQ), a low QC with a concentration three times the LOQ [19], a medium QC and a high QC ranges. Accuracy was measured as the percentage of deviation from the nominal concentrations. All intra- and interday precision should be within a coefficient of variation $(\mathrm{CV} \%)$ of $15 \%$ or less.

2.8.4. Recovery-Recovery is represented as \% extraction efficiency. Extraction efficiency is calculated by dividing the area response of three pre-spiked QC levels (low, medium, and high) by the area response of extracted blank plasma that is post-spiked with the same three QC concentrations.

2.8.5. Limits of quantitation (LOQ) and limit of detection (LOD)-The lower limit of quantitation (LOQ) was defined as the lowest concentration for which both the CV\% and the percent of deviation from the nominal concentration were less than $20 \%$. The upper limit of quantitation (ULQ) was defined as the concentration for which both the CV\% and the percent of deviation from the nominal concentration were less than $15 \%$ [20]. The limit of detection (LOD) was the lowest concentration that the bioanalytical procedure could reliably differentiate an analyte signal to noise ratio of 3:1.

2.8.6. Stability-HIV-infected patient samples are routinely heated at $58-60^{\circ} \mathrm{C}$ to inactivate the virus prior to handling. Heat deactivation studies were performed to verify the stability of all the drugs in plasma under these conditions. An additional stability test was performed to verify the stability of the drugs in the autosampler tubes while waiting for HPLC analysis. Additionally, the samples were left at room temperature for $24 \mathrm{~h}$ prior to analysis. The stability during sample handling was verified by subjecting samples to three freeze-thaw cycles, and 
storage for 7 days in the refrigerator at $4{ }^{\circ} \mathrm{C}$ prior to analyses. Low, medium, and high QC samples were utilized in stability testing.

2.8.7. Method applicability-Clinical samples and external proficiency testing samples were used to test the applicability of the method. Since DRV plasma concentrations may be higher than ETR and RTV, sample dilution was also evaluated. Clinical sample volumes of 50,20 and $10 \mu \mathrm{L}$ were diluted in drug free plasma for investigation of 1:1, 1:4 and 1:9 dilutions.

\section{Results}

\subsection{Method optimization and mobile phase selection}

The best response signal for DRV and ETR occurred with a small percentage of formic acid $(0.01 \%)$ added to the mobile phase. Fig. 2a represents the signal response of the four analytes as peak area plotted against percentage of formic acid. The use of ammonium acetate as a mobile phase modifier was also tested. Fig. $2 b$ demonstrates that the signal response for the four analytes was best with no ammonium acetate added to the mobile phase.

\subsection{Chromatographic separation and selectivity}

Representative chromatograms of a drug free plasma sample with IS, a plasma sample representing the LOQ, and a low and medium QC concentration extracted from human plasma can be found in Fig. 3a-d, respectively. Under the final method's chromatographic conditions, typical retention times of the IS, DRV, RTV and ETR were 1.6, 3.0, 4.7, and $5.4 \mathrm{~min}$, respectively.

\subsection{Linearity and limit of quantification}

The peak area ratio values of the calibration standards were proportional to the concentration of each drug in plasma over the range tested. The calibration curves were fitted by weighted least-squares linear regression. The mean \pm SD of three standard curve slopes for DRV, RTV, and ETR were $621.8 \pm 12.2,808.3 \pm 11.7,811.3 \pm 31.3$, respectively. The concentration range was $0.002-2.0 \mu \mathrm{g} / \mathrm{mL}$ for these three analytes. The regression coefficient $\left(r^{2}\right)$ of all calibration curves was greater than 0.999 . All three analytes were linear in the range of $0.002-2.0 \mu \mathrm{g} / \mathrm{mL}$. The lowest limit of quantification was determined to be $0.002 \mu \mathrm{g} / \mathrm{mL}$ for all analytes.

\subsection{Accuracy, precision and recovery}

Results from the validation of this method in human plasma were acceptable. Precision and accuracy at the lower and upper limits of quantitation are listed in Table 1. Table 2 summarizes the accuracy and precision for four quality control concentrations ranging from 0.006 to 1.8 $\mu \mathrm{g} / \mathrm{mL}$. Intra-day accuracy of all analytes ranged from 89 to $106 \%$ with a mean of $96.4 \%$ and inter-day accuracy ranged from 88 to $104 \%$ with a mean $96.5 \%$. Throughout the concentration range of the control samples, the mean intra-day precision was always lower than $6.6 \%$. Overall, the mean inter-day precision for each the three analytes was 3.7\%, with mean RSDs ranging from 1.9 to $6.4 \%$.

The absolute recovery of all three analytes and internal standard from plasma using the liquidliquid extraction procedure was investigated. This extraction method reliably eliminated interfering material from plasma, with high recovery for DRV (>96\%), ETR (>95.0\%) RTV $(>91.0 \%)$ and the IS alprazolam (>90.0\%). 


\subsection{Stability}

The stability of the three analytes under various conditions is shown in Table 3. Under all conditions tested, the three drugs proved to be stable. All results were within the acceptance criteria of $\pm 15 \%$ deviation from the nominal concentration.

\subsection{Analysis of patient samples and external quality control samples}

We examined the applicability of the described method by analyzing plasma samples collected from HIV-infected patients. Due to the high DRV concentrations in patient plasma, sample dilution may need to be performed. Accuracy of the diluted samples is represented as the percentage of deviation from the measured concentration of the each sample before dilution. Table 4 lists the accuracies of patient samples obtained from varying dilutions. Fig. 4 shows a chromatogram from one of these samples. This sample was diluted 5-fold. This patient was receiving tenofovir and emtricitabine along with DRV, RTV, and ETR. When this method was used to measure 9 external proficiency testing samples for DRV, RTV, and ETR, accuracies ranged from 92 to $107 \%$.

\section{Discussion}

In today's clinical pharmacology environment, highly sensitive and selective bioanalytical methods are required. Laboratories designed for conducting pharmacokinetic studies must validate methods not only to meet industry guidelines, but also to assure the method's applicability with a given clinical study. This work describes the development, successful validation, and clinical applicability of a novel bioanalytical method for simultaneously analyzing two new antiretroviral agents (ETR, DRV) along with RTV in human blood plasma.

During method development, a number of challenges were addressed. Due to the unfavorable solubility of ETR, it was critical to keep all three analytes in a high percentage of organic solution (3:1 methanol:HPLC-water) before spiking the matrix to create the working solutions. In addition, using a highly organic reconstitution solution (1:3 mobile phase A:mobile phase B) was necessary to assure complete dissolution of ETR before injection onto the HPLC instrument. Consistent results were obtained by using this solution, along with thorough mechanical vortex-mixing after sonication.

During development, several columns were tested. We began with a Zorbax ${ }^{\circledR}$ XDB C8 column, $150 \mathrm{~mm}$ in length with an internal diameter (ID) of $4.6 \mathrm{~mm}$ and a particle size of $5 \mu \mathrm{m}$. We have previously used this column to analyze three non-nucleosides; nevirapine, delavirdine, and efavirenz [21]. It demonstrated good analyte separation for DRV, RTV, ETR, and the IS. To shorten the run time, we also investigated the same column in several different dimensions. The chosen column was Agilent Zorbax XDB C8 column with a $3.0 \mathrm{~mm}$ ID, $50 \mathrm{~mm}$ in length, and a particle size of $1.8 \mu \mathrm{m}$. This column demonstrated the best separation and peak shape with a short run time.

This optimized LC-MS method provides not only fast, but also sensitive, measurement for simultaneously determining the concentration of ETR, DRV, and RTV. The sensitivity was achieved by careful mobile phase selection. Optimal ionization of the three analytes and internal standard was investigated for various concentrations of formic acid and ammonium acetate.

The data demonstrate that alprazolam was a suitable choice as an IS. It was well separated from the assay analytes, it ionized positively under the same conditions as the other analytes, and most importantly, it extracted reliably with good recovery. 
Since combination therapy with DRV, ETR, and RTV may also include other antiretroviral drugs, the analytical method was tested for possible interferences from 16 other antiretrovirals. The back calculated QC concentrations investigated proved that the assay analytes can be accurately measured in the presence of these potentially co-administered drugs. Recently, Viard and et al. [22] published an HPLC-UV method for DRV. However, as this method is unable to separate amprenavir (APV) from DRV, it may be somewhat limited when studying patients on combination antiretroviral therapy. Also, D'Avolio et al. [23] published HPLCPDA method for ETR, DRV, and RTV with many other common antiretroviral agents.

Although their method was able to analyze fifteen antiretroviral agents, our method is more sensitive and can be used in measuring triplicate therapy in rare matrices utilizing small sample volumes.

Finally, the quality and accuracy of described method was tested using the ACTG antiretroviral quality assurance (2007 and 2008 QA samples) program [24]. Accuracies ranged from 92 to $107 \%$ for two separate testing round of proficiency testing samples with DRV and RTV and one testing round with ETR.

\section{Conclusion}

A successfully developed and validated LC-MS bioanalytical method for DRV, RTV, and ETR in human plasma has been described. This method was optimized using a sub-2 $\mu \mathrm{m}$ column, and is quick, accurate, sensitive, specific, and highly reproducible. It demonstrates good linearity, precision and accuracy within a wide concentration range $(0.002-2.0 \mu \mathrm{g} / \mathrm{mL})$. The liquid-liquid extraction method is simple, results in high analyte recovery and increase method specificity. This method is currently being used for investigations of both HIV-negative and HIV-positive subjects.

\section{Acknowledgement}

This research was supported by The University of North Carolina at Chapel Hill Center for AIDS Research, \#9P30 AI50410.

\section{References}

1. Vingerhoets J, Azijn H, Fransen E, De I, Baere L, Smeulders D, Jochmans K, Andries R, Pauwels MH, Azijn T, Thielemans D, ludovici M, Kukla J, Heeres P, Janssen J, Vingerhoets M, de Bethune. J. Virol 2005;79:12773. [PubMed: 16188980]

2. Andries K, Azijn H, Thielemans T, ludovici D, Kukla M, Heeres J, Janssen P, De Corte B, Vingerhoets J, Pauwels R. Antimicrob. Agents Chemother 2004;48:4680. [PubMed: 15561844]

3. [06/18/06]. FDA-Prezista Approval Letter, Available at: http://www.fda.gov/cder/foi/appletter/2006/021976s0001TR.pdf

4. King NM, Prabu-Jeyabaln M, Nalivaika EA, Wigerinck P, deBethune M-P, Schiffer CA. J. Virol 2004;78:12012. [PubMed: 15479840]

5. [06/09/07]. Tibotec-Prezista Prescribing Information, June 2006, p. 9. Available at: http://www.prezista.com

6. [06/19/07]. Tibotec-Prezista, Available at: http://www.tibotec.com

7. Koh Y, Nakata H, Maeda K, Ogata H, Bilcer G, Devasamudram T, Kincaide JF, Boross P, Wang YF, Tie Y, Volarath P, Gaddis L, Harrison RW, Weber IT, Ghosh AK, Misuya H. Antimicrob. Agents Chemother 2003; 74:3124.

8. DeMeyer S, Azijin H, Jochmans D, Tahri A, Pauwels R, Wigwrinck P, de Bethune M-P. Antimicrob. Agents Chemother 2005;49:2314. [PubMed: 15917527]

9. Poveda E, Blanco F, Gacia-Gasco P, Alcolea A, Soriano V. Aids 2006;20:1558. [PubMed: 16847414] 
10. Molina, JM.; Katlama, C.; Grinsztejn, B.; Timerman, A.; Perdo, R.; De Meyer, S.; de Bethune, MP.; Tvangeneugden; Lefebvre, E. Proceedings of the XVI International AIDS Conference; Toronto, Canada TUPE 0060. 2006.

11. Carpenter CCJ, Fischl MA, Hammer SM, et al. J. Am. Med. Assoc 1997;277:1962-1969.

12. Gulick RM, Mellors JM, Havler D, et al. N. Engl. J. Med 1997;337:734-739. [PubMed: 9287228]

13. Cavert W, Notermans DW, Staskus K, et al. Sciences 1997;276:960-964.

14. Hammer SM, Saag MS, Schechter M, Montaner JS, Schooley RT, Jacobsen DM, et al. JAMA 2006;296:827. [PubMed: 16905788]

15. Gallant JE, DeJesus E, Arribas JR, Pozniak AL, Gazzard B, Campo RE, et al. N. Engl. J. Med 2004;354:251. [PubMed: 16421366]

16. DeJesus E, Herrera G, Teofilo E, Gerstoft J, Buendia CB, Brand JD, et al. Clin. Infect. Dis 2004;39:1038. [PubMed: 15472858]

17. Boffito M, Winston A, Jakson A, Flectecher C, Pozniak A, Nelson M, Moyle G, Yolowinska I, Hoetelman R, Miralles D, Gazzard B. AIDS 2007;21:1449. [PubMed: 17589191]

18. Mallon PWG, Ray J, Cooper DA. J. Clin. Virol 2003;26:223. [PubMed: 12600653]

19. US Department of Health and Human Services Food and Drug Administration. Guidance for Industry. [6/1/2008]. Biological Method Evaluation Available at: http://www.fda.gov/cder/guidance/

20. Shah VP, Midha KK, Findlay JW, Hill HM, Hulse GO, Gilveray J, Mckay G, Miller KJ, Patnaik RN, et al. Pharm. Res 2001;17(120):1551. [PubMed: 11303967]

21. Rezk NL, Tidwell R, Kashuba ADM. J. Chromatogr. B 2002;774:79.

22. Goldwirt L, Chhun S, Rey E, Launay O, Viard J-P, Pons G, Jullien V. J. Chromatogr. B 2007;857:327.

23. D'Avolio A, Baietto L, Sicardi M, SCiandra M, Simiele M, Oddone V, Bonora S, Di Perri G. Ther. Drug Monit 2008;30(6):662. [PubMed: 18824956]

24. Holland DT, DiFrancesco R, Stone J, et al. Antimicrob. Agents Chemother 2004;48:824. [PubMed: 14982771] 


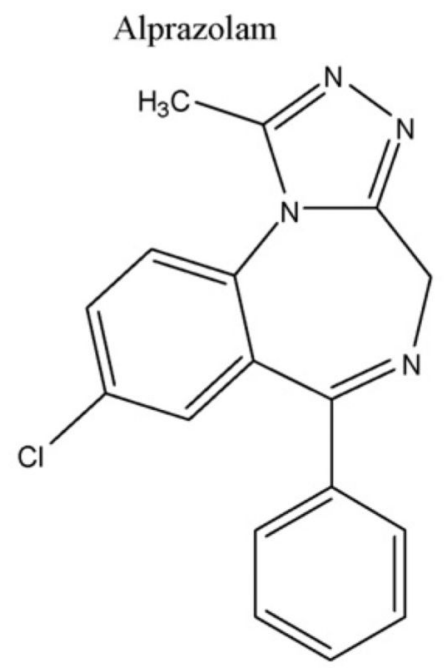

Darunavir

Etravirine

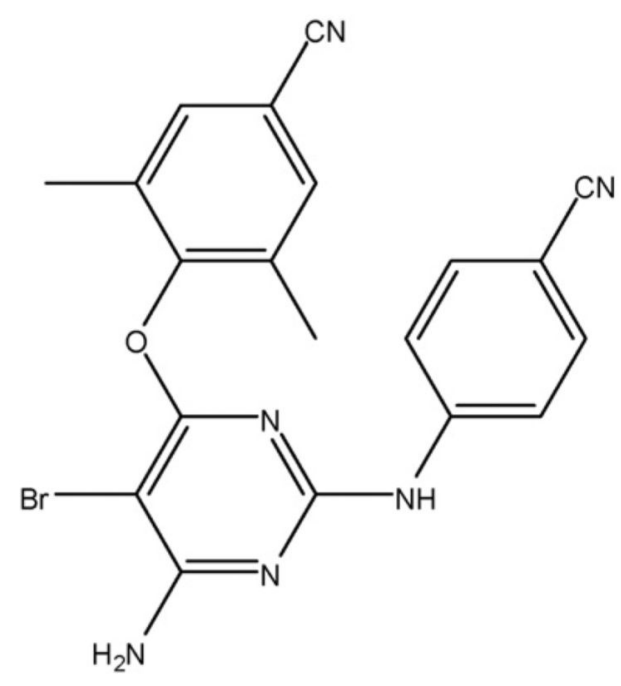

Ritonavir<smiles>CC(C)c1nc(CN(C)C(=O)N[C@H](C(N)=O)C(C)C)cs1</smiles><smiles>CC[C@H](N)Cc1ccccc1</smiles><smiles>CC(C)CN(C[C@H](O)[C@H](Cc1ccccc1)NC(=O)O[C@H]1CO[C@H]2OCC[C@H]12)S(=O)(=O)c1ccc(N)cc1</smiles> 

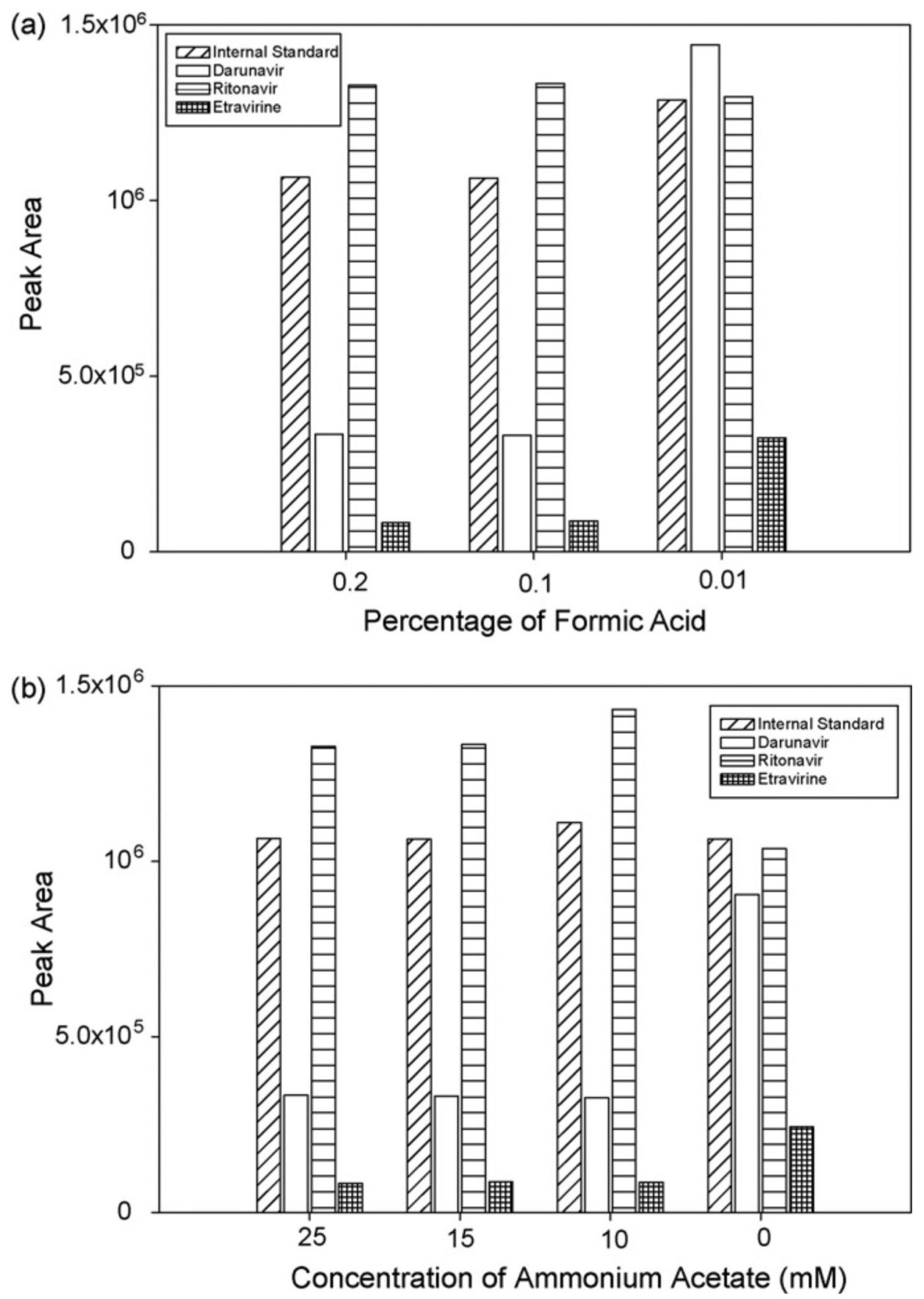

Fig. 2.

(a) The effect of the formic acid in the mobile phase on analyte response. (b) The effect of ammonium acetate buffer in the mobile phase on analyte response. 

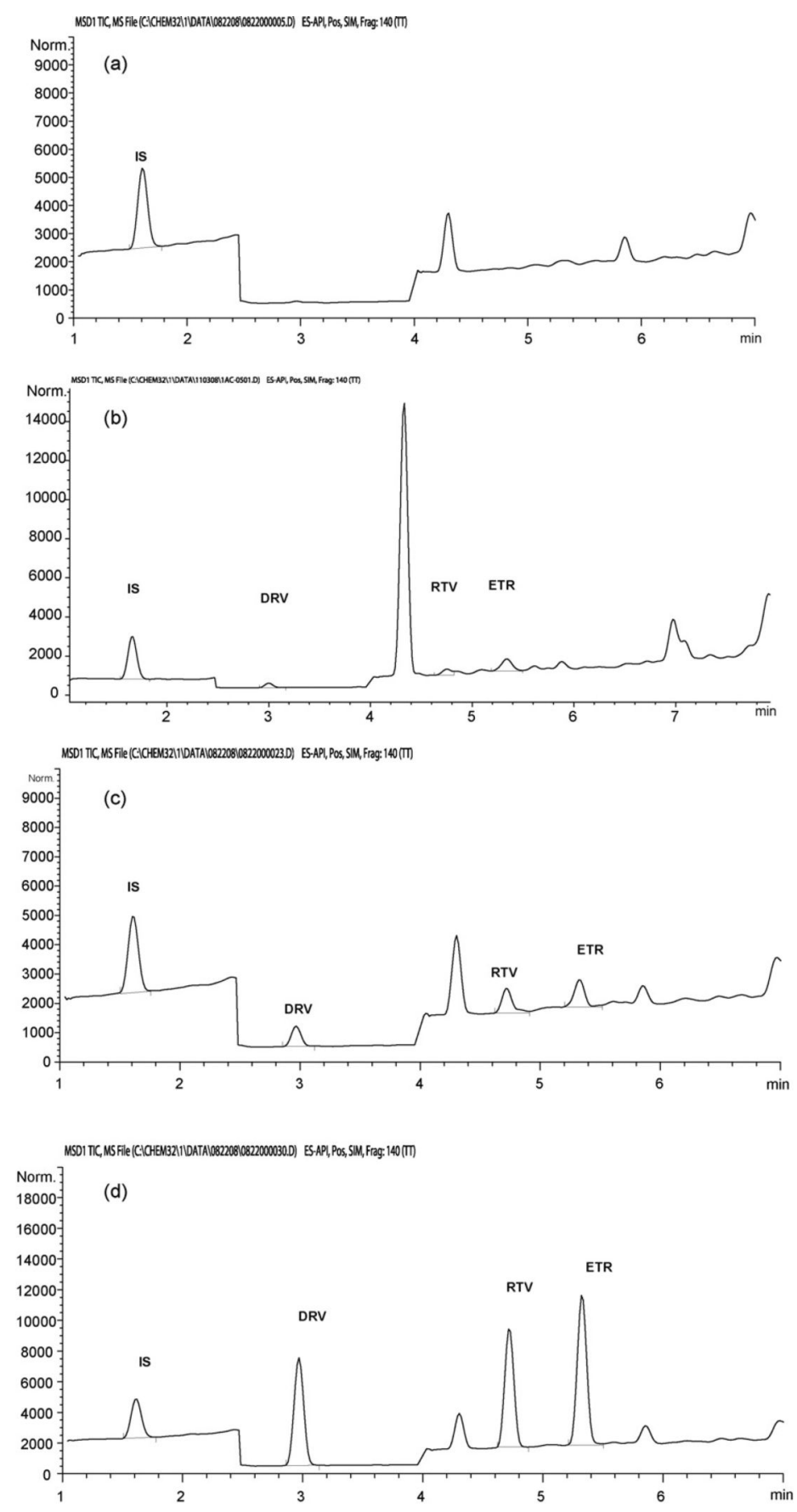

Fig. 3.

(a) Chromatogram of extracted blank plasma with internal standard. (b) Chromatogram of extracted $0.002 \mu \mathrm{g} / \mathrm{mL}$ (LOQ) from human plasma. (c) Chromatogram of extracted $0.006 \mu \mathrm{g}$ / $\mathrm{mL}$ (low QC) from human plasma. (d) Chromatogram of extracted $0.06 \mu \mathrm{g} / \mathrm{mL}$ (medium QC) from human plasma. 


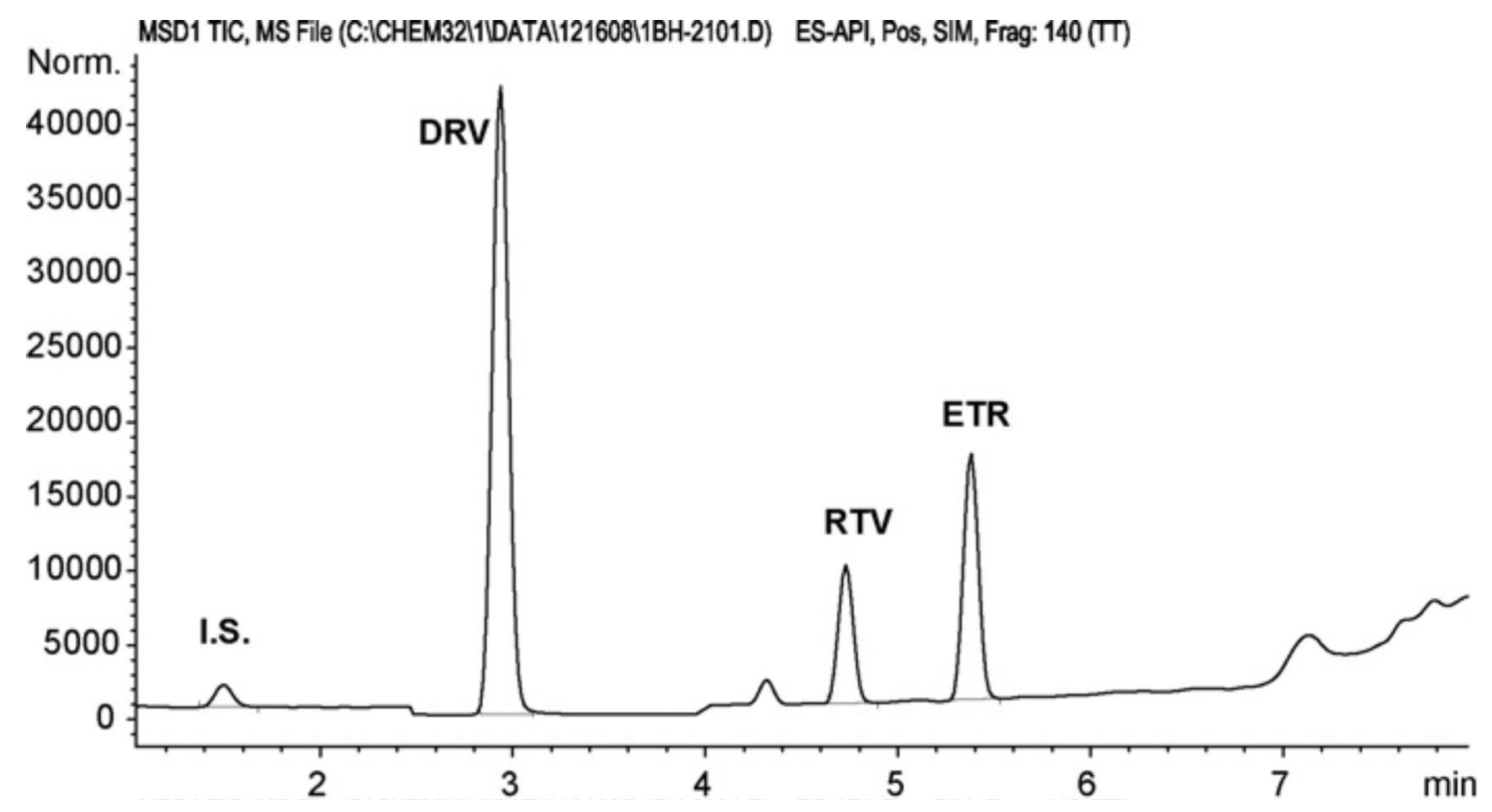

Fig. 4.

Chromatogram of a patient sample (diluted 5-folds) containing DRV, RTV and ETR. The concentration of DRV was $5.193 \mu \mathrm{g} / \mathrm{mL}$, RTV $0.582 \mu \mathrm{g} / \mathrm{mL}$ and ETR $0.719 \mu \mathrm{g} / \mathrm{mL}$. 


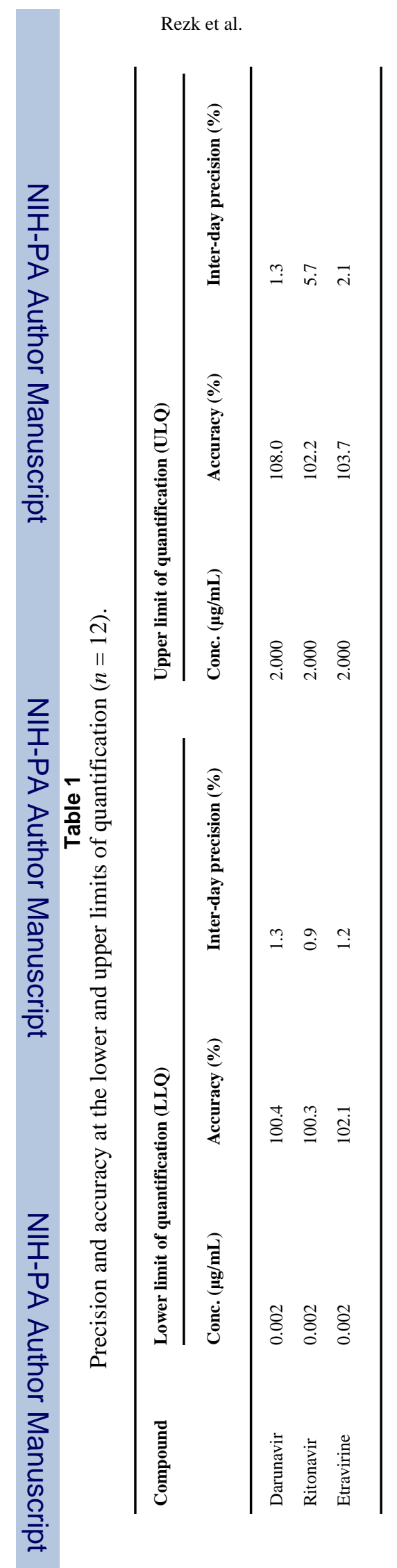

Talanta. Author manuscript; available in PMC 2010 October 15. 


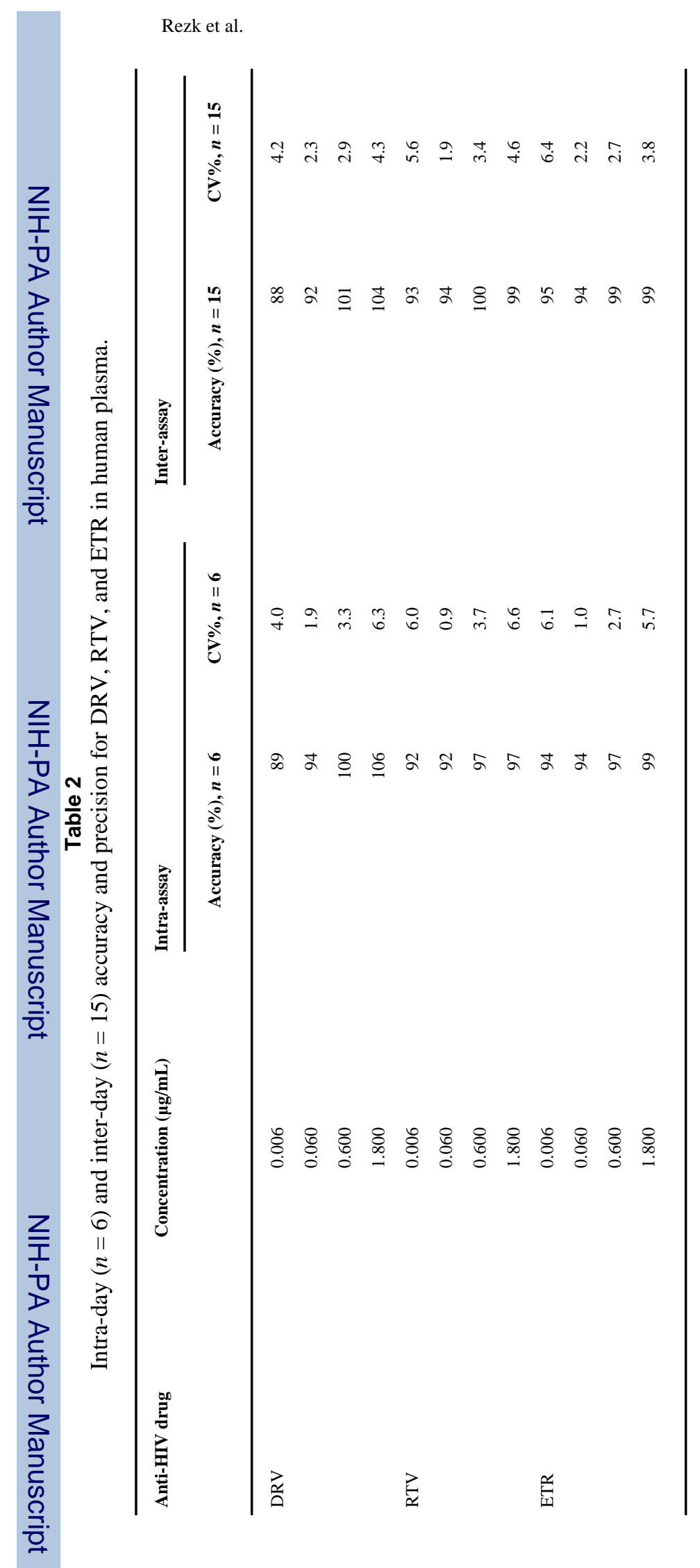

Page 14 


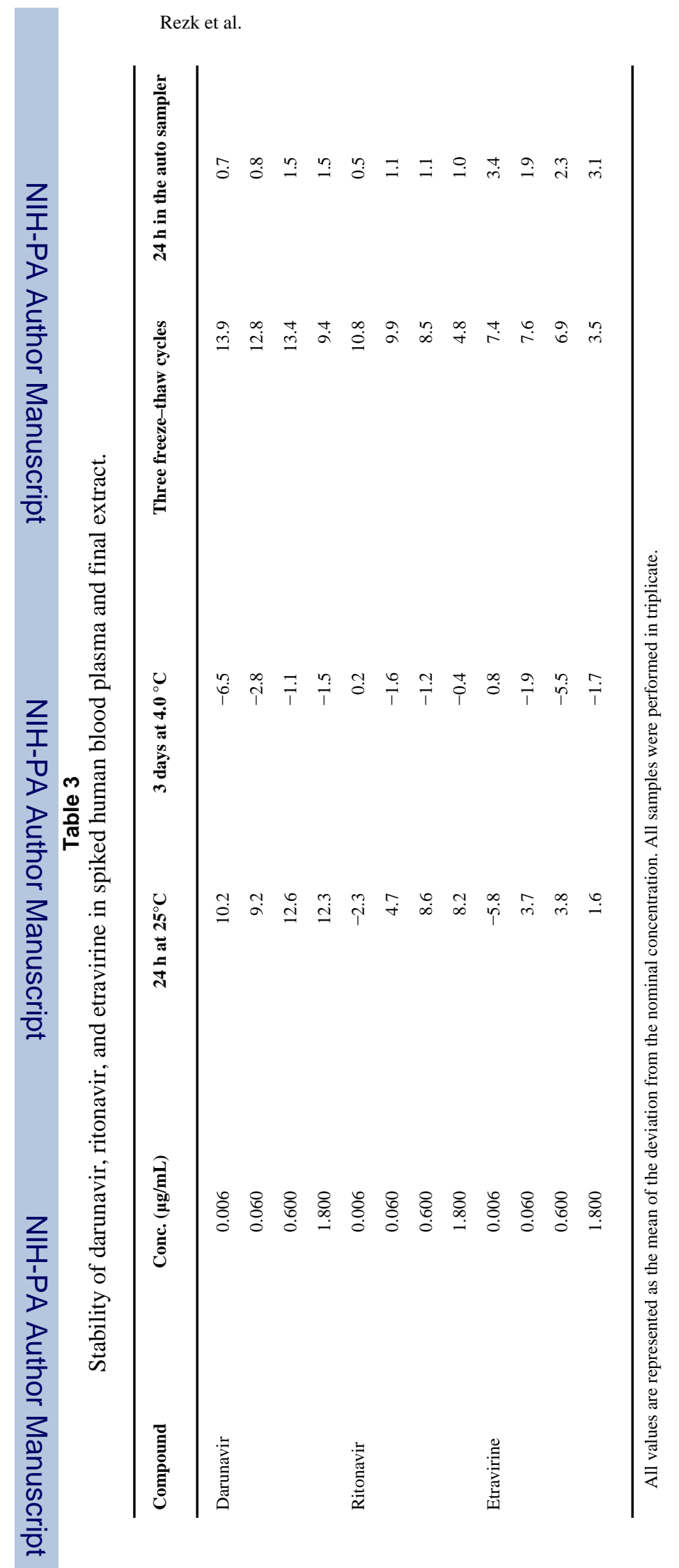

Page 15 
Table 4

Average accuracies for diluted clinical samples (2-, 5- and 10-fold dilutions of 10 samples).

\begin{tabular}{llll}
\hline Compound & Dilution 1:1 \% dev & Dilution 1:4 \% dev & Dilution 1:9 \% dev \\
\hline Darunavir & 5.19 & -2.11 & -4.05 \\
Ritonavir & 6.75 & -0.87 & -4.86 \\
Etravirine & 2.86 & -4.5 & -8.58 \\
\hline
\end{tabular}

